\title{
GUARDIANSHIP FOR MINORS AND ADULTS IN THE SOCIAL WELFARE SYSTEM OF CROATIA
}

Croatia has extensive legal framework for guardianship system for minors and adults, regulating situations in which court or other competent institution has a duty to appoint a guardian to safeguard interests of either a child deprived of parental care or where the holders of parental responsibility cannot ensure the child's best interest and/or represent the child, unaccompanied child migrant, minor victim of trafficking of adult person who is due to mental disability unable to protect his/her own interests. Article 12 of the Convention on the Rights of Persons with Disabilities stipulates obligation of States Parties to ensure that persons with disabilities have the right to recognition everywhere as persons before the law and that they recognize their legal capacity on an equal basis with others in all aspects of life, along with support they may require in exercising their legal capacity. As the role of guardian is often unclear and insufficiently regulated, practical implementation of guardianship is difficult or even impossible in some cases, thus affecting fundamental rights of a minor or adult under guardianship system. In social welfare, this is particularly concerning as persons under guardianship are usually in serious social risk and very vulnerable to exploitation of all kinds. Social workers are thus in a position to represent interests of the most deprived and disempowered and they should do it in an empowering manner, ensuring their social and legal equality. The paper provides analysis of the current legal regulation of guardianship for minors and adults in Croatia, looking into the main challenges of the guardianship system for both categories of beneficiaries. It emphasises inconsistencies of current legal regulation with international human rights law and points out the main areas where the system needs to be changed in accordance with the advanced models of guardianship system. Paper also provides examples of guardianship systems for unaccompanied minors in selected European countries which differ depending on whether they appoint professional guardians (usually Social Workers or Lawyers) or volunteer guardians without power to represent children before the courts. The aim of the paper is to contribute to legal discussions on the national guardianship system which

* Associate Professor, Department of Labour and Social Law and Social Work, Faculty of Law Osijek, Croatia. E-mail: hspadina@pravos.hr. 
is effective and protects the interests of beneficiaries in the best possible way and in line with the international human rights law, possibly providing guidance on managing and strengthening guardianship systems in Croatia.

Keywords: guardianship, unaccompanied minors, disabled adults, social welfare system.

\section{INTRODUCTORY REMARKS}

Discussion about guardianship system and role of social workers in representing minors or incapacitated adults often assumes that it is a clear-cut case of unavoidable necessity to provide legal protection to those who need it, where a professional makes so-called surrogate decisions. ${ }^{334}$ In reality, we have numerous legal challenges, starting from legal justification of deprivation of legal capacity from an adult person, the question whether deprivation of legal capacity could be replaced by an adequate decision-support system, possible abuses of legally incapacitated persons in business dealings and of admission to institutional care decisions, challenges related to the implementation of international legal instruments regulating rights of persons with disabilities and children, incompatibility of certain roles of Social Workers with guardianship, particularly gerontological Social Workers working in institutional care of elderly or Social Workers working in inclusion housing units with persons of impaired mental health, inability of Social Workers to handle the large caseload of guardianship cases, problems with representation of interest of unaccompanied minor migrant children and many more challenges. If we assume that guardianship's major goal should be promotion of social justice and human rights, we need to look into the legal gaps in present regulation of guardianship and for that purpose, we will use Croatia as a case study.

The paper analyses the roles and responsibilities of Social Workers in guardianship of children and adults. Persons under guardianship are usually in serious social risk and are especially vulnerable to exploitation. Social Workers are consequently in a position to represent interests of the most deprived and disempowered, and they should do it in an empowering manner, ensuring their social and legal equality and ultimately, social justice.

The paper is divided into five parts, starting from Chapter 2. In the second Chapter, I set out the principles of legal capacity and minor and adult legal guardianship, outlining the position of guardianship system within the social protection scheme, followed by a description of guardians' basic roles and functions, including the role of a guardian as a link between different actors and presenting comparative solutions for appointment of guardians. The third Chapter focuses on child guardianship in general, the fourth Chapter deals with child guardianship in Croatia, while the fifth Chapter focuses on the roles and responsibilities of appointed child guardians (usually Social Workers) to unaccompanied minor migrants, outlining current issues in implementation of this institute. In Chapter 6, the focus is on legal incapacitation due to disability. This Chapter seeks to answer the question whether deprivation of legal capacity is (ab)used to compensate for a lack of appropriate supporteddecision, co-decision, and other forms of support disabled persons need in their daily life.

${ }^{334}$ Crampton, A., 2004, The Importance of Adult Guardianship for Social Work Practice, Journal of Gerontological Social Work, 43:2-3, 117-129, DOI: 10.1300/J083v43n02_08. 
The main research question is whether Croatian social policies regulating guardianship, as the most invasive legal intervention to protect children without parental care or incapacitated adults, are designed to promote supported decision-making, rather than substituted decision-making. I explore whether guardianship in Croatia is currently used to fill the gaps in insufficient legal, social and other support in decision-making for mentally impaired persons, so that national legislation is more aligned with the international legal standards, providing sufficient safeguards to protect fundamental human rights of persons under guardianship.

\section{PRINCIPLES OF LEGAL CAPACITY AND GUARDIANSHIP}

In order to understand the institute of guardianship, we need to clarify the notion of legal capacity. Council of Europe defines legal capacity as a person's power or possibility to act within the framework of the legal system, to be subject of a law and to enable people to have rights and obligations, to make binding decisions and have them respected. ${ }^{335} \mathrm{It}$ further distinguishes between the capacity to have rights and capacity to act or exercise these rights Notably, the Convention on Rights of Persons with Disabilities ${ }^{336}$ vests persons with disabilities with both of these aspects of legal capacity, stating that "the capacity to be both a holder of rights and an actor under the law." Convention further clarifies that "Legal capacity to be a holder of rights entitles a person to full protection of his or her rights by the legal system. Legal capacity to act under the law recognizes that person as an agent with the power to engage in transactions and create, modify or end legal. ${ }^{337}$ The UN Committee on the Rights of Persons with Disabilities describes legal capacity as "the capacity to be both a holder of rights and an actor under the law. Legal capacity to be a holder of rights entitles a person to full protection of his or her rights by the legal system. Legal capacity to act under the law recognizes that person as an agent with the power to engage in transactions and create, modify or end legal relationships." 338 Therefore, the Committee explains that "legal capacity is the ability to hold rights and duties (legal standing) and to exercise those rights and duties (legal agency)." 339

Guardianship was initially developed as a legal and social tool to protect vulnerable persons, either adults who cannot adequately protect their own interests and well-being

\footnotetext{
${ }^{335}$ Council of Europe, Commissioner for Human Rights, 2021, Who gets to decide? Right to legal capacity for persons with intellectual and psychosocial disabilities, pp. 10-11.

${ }^{336}$ Convention on the Rights of Persons with Disabilities Official Gazette - International Agreements, No. 06/07, 03/08 and 05/08.

${ }^{337}$ Dhanda, A., 2007, Legal capacity in the Disability Rights Convention: Stranglehold of the past or lodestar for the future?, 34 Syracuse Journal of International Law \& Commerce, p. 429ff; Bach, M., Kerzner, L., 2010, A New Paradigm for Protecting Autonomy and the Right to Legal Capacity', prepared for the Law Commission of Ontario, p 16; Minkowitz, T, 2007, The United Nations Convention on the Rights of Persons with Disabilities and the right to be free from nonconsensual psychiatric interventions, 34 Syracuse Journal of International Law \& Commerce, p. $405 f$.

${ }^{338}$ Committee on the Rights of Persons with Disabilities, General comment No. 1 (2014), Article 12: Equal recognition before the law, $\mathrm{CRPD} / \mathrm{C} / \mathrm{GC} / 1, \mathrm{p} .3$, point 12 .

${ }^{339}$ Ibid.
} 
and for whom a legal intervention is used through the appointment of a surrogate decision maker ${ }^{340}$ and children deprived of parental care or in a legal position where parents cannot participate in decision making for the well-being of children.

Guardianship of an adult is a legal court order which gives an individual (the guardian) the legal authority and responsibility to make or assist in making decisions about personal matters on behalf of another adult. ${ }^{341}$ We have to understand that adult persons under full guardianship are invisible in society, unable to make any legally enforceable decision and legally non-existent. This is why we need to engage in serious considerations of the applicability of guardianship for adults, the process for the selection and appointment of guardians for children and adults, roles and responsibilities of guardians and legal implications of guardianship decisions. It is of utmost importance to have precise and human-rights-based legal regulation of the scope of guardianship, including skills and necessary professional competencies of Specialized Guardians, among which Social Workers are most frequently appointed as specialized guardians to both children and adults. If guardianship system is abused to circumvent involuntary institutionalization or hospitalization, conclusion of a legal contract or any other task of importance for a future life of an adult beneficiary, if child's wishes and opinions are not taken into consideration, or if specialized guardian simply does not have the opportunity to meet a child under his guardianship, it is evident that the main purpose of guardianship is not being achieved in practice, despite comprehensive international human rights standards and national legislation, which can be excellent in formal regulation of guardianship.

Different types of guardianship are applicable, depending on the legal system where the guardianship takes place. The main difference that can be identified is that between permanent guardianship, where, for example, permanent mental impairment is assessed to justify appointment of a permanent guardian, and temporary guardianship, which is usually reserved for special situations where, for example, legal guardians (such as parents) are temporarily prevented from performing their legal duties. There is also emergency guardianship that can be used in crisis situations, where the health or safety of a person is endangered.

Further, we have a crucial distinction between plenary and partial guardianship for adults. The Committee on the Rights of Persons with Disabilities clarified in 2014 that substitute decision-making regimes can include plenary (permanent) guardianship, judicial interdiction and partial guardianship. The Committee explained that "in all cases of substitute-decision making a legal capacity is removed from a person, a substitute decision-maker can be appointed by someone other than the person concerned, and this can be done against his or her will; and any decision made by a substitute decision-maker is based on what is believed to be in the objective "best interests" of the person concerned, as opposed to being based on the person's own will and preferences."

Adult legal guardianship is activated in all cases when an adult is deprived of legal capacity, either partially or fully. This is mainly applicable in cases of mental illness or a similar state in which a person cannot make the necessary decisions and cannot

\footnotetext{
${ }^{340}$ Burningham, S., 2009, Developments in Canadian Adult Guardianship and Co-Decision-Making Law, 8 Dalhousie J. Legal Stud. 119.

${ }^{341}$ Government of Alberta, Canada, https://open.alberta.ca/publications/guardianship-general-overview.
} 
comprehend his/her own best interests. In all cases of partial or full deprivation of legal capacity of a person with mental disability, the appointed legal guardian implements socalled substitute -decision making.

In 2012, the Council of Europe Commissioner for Human Rights recommended "abolishment of mechanisms providing for full incapacitation and plenary guardianship." This recommendation is in line with the provisions of the Convention on the Rights of Persons with Disabilities, according to which States should refrain from any action that deprives persons with disabilities of the right to equal recognition before the law and full and effective participation and involvement in society, with plenary guardianship or any other form of substitute-decision making being considered to be among such deprivations. Convention requires the signatory states to accept that persons with disabilities have the legal capacity on the same basis as other persons in all aspects of life, and signatory parties are obliged to take targeted measures to provide assistance to persons with disabilities to exercise their legal capacity, including the right to supported decision-making procedures. The shift from substitute-decision making to supported-decision making is a key legal development for persons with disabilities and presents the human rights-based model of disability.

Application of supported-decision making model would, naturally, never imply full abolition of deprivation of legal capacity for persons who are medically assessed as unable to protect their own interests and understand implications of their decisions. Instead, it would provide opportunities to those disabled persons who are able to protect their own interests and well-being and to become fully recognized members of society.

Appointment of a guardian for adults is always linked to the assessment of mental and legal capacity. When it comes to children, it is linked to the assessment of their particular situation, where the professionals have to decide whether the child's interest would be best protected by the legal substitute to their parents - guardians. ${ }^{342}$

While we often assume that a guardian needs to be able to legally represent an adult or a minor, this is not always the case. Sometimes guardians are indeed legal representatives, but in many other cases they are just "guards of special interests" and have no power to represent their wards legally, but instead decide on a whole range of personal issues. Thus, we have a group of European countries where legal guardians are always professional caregivers -in Germany, the United Kingdom and countries of South-East Europe, including Croatia, they are mostly social workers appointed ex officio. ${ }^{343}$ In Italy, we have an interesting practice that legal guardian is usually the mayor of the city where the minor is located, but if another person apart mayor is appointed, there is no legal requirement on who that can be - the only requirement is that a guardian is a person of good conduct and suitable for the job. ${ }^{344}$ In the Netherlands, children's legal guardians are so-called youth protectors.

The second group of countries establishes child guardianship as a volunteer task, except for legal representation. In Belgium, child guardianship is currently a combination of

${ }^{342}$ Burningham, S., 2009, Developments in Canadian Adult Guardianship and Co-Decision-Making Law, 8 Dalhousie J. Legal Stud. 119.

${ }^{343}$ NIDOS Foundation, 2005, Towards a European Network of Guardianship Institutions, pp. 29-32, https:// www.nidos.nl/en/home/nidos-en-europa/european-guardianship-network-egn/

${ }^{344}$ Ibid. pp. 39-43. 
gratuitious and professional guardianship. ${ }^{345}$ Interesting solution exists in France where there are three types of guardianship: tutelle, educateur and ad-hoc administrator. ${ }^{346}$

Various practices in this regard are the result of a lack of commonly agreed definition of guardianship for children in the European Union. ${ }^{347}$ This poses a problem because it is difficult to compare various legal solutions in different Member States.

Canadian law requires guardians to act in the adult's best interest, to be diligent and act in good faith, to encourage the adult to be as independent as possible, to act in the least intrusive and restrictive manner (that is effective), to inform the adult of important decisions that are made and to keep a record of the decisions that are made. A guardian has a responsibility to only access information that has been authorized and is needed for a given decision and keeps personal information about the adult safe from unauthorized access, use or disclosure.

A Canadian co-decision maker shares legal authority with the adult, must consent to an adult's reasonable decisions and is statutorily required to minimally interfere in the adult's life and decision- making process and he is required to act in a manner that protects the adult's civil and human rights.

\section{LEGAL GUARDIANSHIP OF CHILDREN}

According to the UN Committee on the Rights of the Child:

"A guardian is an independent person who safeguards a child's best interests and general well-being, and to this effect complements the limited legal capacity of the child. The guardian acts as a statutory representative of the child in all proceedings in the same way that a parent represents his or her child." ${ }^{348}$

Without commonly agreed definition of legal guardianship, we are deriving the current concepts of legal protection of children from the principles from the United Nations Convention on the Rights of the Child. ${ }^{349}$ The Convention regulates key principles related to the guardian's work, primarily through Article 2 governing non-discrimination, Article 3 defining the best interests of a child and Article 12 prescribing the right of a child to express his/her views and to be heard in any judicial and administrative proceedings

\footnotetext{
${ }^{345}$ Ibid. pp. 12-16.

${ }^{346}$ Ibid. pp. 23-27.

${ }^{347}$ European Union Agency for Fundamental Rights, 2014, Guardianship for children deprived of parental care, A handbook to reinforce guardianship systems to cater for the specific needs of child victims of trafficking, p. 13.

${ }^{348}$ UN Committee on the Rights of the Child General Comment No. 6 CRC/GC/2005/6 and the UN Alternative care guidelines A/HRC/11/L.13, cited in: European Union Agency for Fundamental Rights, 2014, Guardianship for children deprived of parental care, A handbook to reinforce guardianship systems to cater for the specific needs of child victims of trafficking.

${ }^{349}$ Convention on the Rights of the Child, Adopted and opened for signature, ratification and accession by General Assembly resolution 44/25 of 20 November 1989, entry into force 2 September 1990, in accordance with article 49.
} 
affecting the child, either directly, or through a representative or an appropriate body, in a manner consistent with the procedural rules of national law.

Child legal guardianship needs to be based on common fundamental principles, including quality, child participation, non-discrimination, sustainability, independence, impartiality and accountability. ${ }^{350}$

When considering the main functions of a legal child guardian, we can distinguish three main functions: insuring child's overall wellbeing (including undertaking of risk assessment, individual needs assessment, provision of support in maintaining the family links, making sure the child has an adequate standard of living, healthcare, education and training), safeguarding the child's best interest and legal representation and complementing the child's limited legal capacity. ${ }^{351}$

The child guardian should act as a link between the child and specific professionals working in various systems important for the healthy development of a child, such as education, justice, welfare and health systems; further the guarding is a link between a child and community and family. ${ }^{352}$ A guardians should ideally facilitate child's full participation in all above mentioned systems, in accordance with the age and maturity of the child. In cases of unaccompanied children, a guardian should assist in identifying a durable solution that is in the child's best interest, which might include foster family care, adoption or return to the country of origin if family members are known and able to undertake care duties over child. ${ }^{353}$

\section{LEGAL GUARDIANSHIP OF CHILDREN IN PRACTICE IN CROATIA}

Legal guardianship in Croatia is regulated by the Constitution of the Republic of Croatia (through protection of social rights and guarantees for social welfare state). Article 58 provides legal basis for state protection of weak, disabled, incapacitated and persons otherwise without proper care, with particular focus on children and youth in general (Article 63 of the Constitution) and children without parental care in Article $64 .{ }^{354}$ Additionally, legal guardianship is regulated in several laws, but the most important provisions related to the legal guardianship of minors and adults are found in the Family Law. ${ }^{355}$

Croatian Family Law prescribes that the court will deprive the parent of the right to parental care in proceedings when it finds that the parent is abusing or grossly violating

\footnotetext{
${ }^{350}$ FRA, p. 13.

${ }^{351}$ Ibid.

${ }^{352}$ Ibid.

${ }^{353}$ Ibid.
}

354 Constitutional of Republic of Croatia, (Official Gazette Number 56/90, 135/97, 08/98, 113/00, 124/00, 28/01, 41/01, 55/01, 76/10, 85/10, 05/14).

${ }^{355}$ National legal framework for the guardianship in Croatia:

Family Law (Official Gazette Number 103/15, 98/19),

Law on Center for Specialized Legal Guardianship (Official Gazette Number 47/20),

Law on Protection of Persons with Mental Disabilities (Official Gazette Number 76/14),

Law on Social Work, (Official Gazette Number 16/19),

Law on Social Welfare (Official Gazette Number 157/13, 152/14, 99/15, 52/16, 16/17, 130/17, 98/19, 64/20, 138/20). 
parental responsibility, duty and rights. ${ }^{356}$ If parents are unable to engage in protection of child's interests, Article 218 of the Family Law is activated, triggering appointment of a legal guardian ${ }^{357}$ Guardianship protection should be adequate, individualized and in accordance with the well-being of the child, taking particular interests of the protection of health, education, personal and property rights of a child. ${ }^{358}$ This, depending on the circumstances, can take a form of definite or indefinite representation of child's interests. ${ }^{359}$ If the Centre for Social Welfare initiates proceedings in the name and on behalf of the child for the purpose of establishing paternity and for the maintenance of the child, it has the position of the child's legal representative in that procedure. ${ }^{360}$

Croatian law recognizes appointment of a guardian to children (nationals or foreigners) to represent them before the court or other state bodies. This legal representation is regulated by the Law on Centres for Specialized Legal Guardianship. The Specialized Guardian for Court representation is a jurist with a right to legal representation. If a child needs a guardian for other non-legal representation tasks, one can be appointed by the Centre for Social Welfare; these are usually social workers, psychologists, social pedagogues or jurists employed by the Centre.

Croatian law further stipulates three main tasks of the Specialized Child Guardian: to represent the child in the proceedings for which he/she has been appointed, to inform the child about the subject matter of the dispute, the course and outcome in a manner appropriate to the child's age and, if necessary, to contact a parent or other person chosen by the child. ${ }^{361}$

Family Law stipulates that a Specialized Guardian will be appointed in all matrimonial disputes and in proceedings in which maternity or paternity are challenged, in proceedings in which parental care, scope of parental care and personal relations with the child are decided on, when there is a dispute between the parents or child care-givers, in the procedure of imposing measures for the protection of personal rights and welfare of the child within the jurisdiction of the court, in the process of making a decision that replaces the consent to adoption, when there is a conflict of interest in property proceedings or disputes, when concluding certain legal transactions or in a dispute or conclusion of a legal transaction between the child and the parent or other person exercising parental care over the child, to a foreign citizen or a stateless child who is found in the territory of the Republic of Croatia unaccompanied by a legal representative and in all other cases when it is necessary to protect the rights and interests of the child. ${ }^{362}$

Ombudsperson for Children reported several issues with the implementation of abovementioned legal provisions of the Family Law. Namely, in the Annual Report for 2020, she

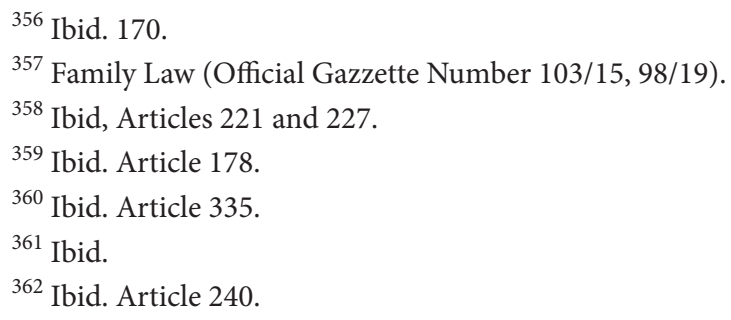


reports a lack in number of appointed Specialized Child Legal Guardians and consequently their inability to cover all guardianship cases due to distances between the regions and cities where children live and where the Courts are located. ${ }^{363}$ This leads to insufficient number of contacts with children to establish trust. ${ }^{364}$ Another concern raised is over the skills and professional competencies of jurists to communicate with children in vulnerable situations and the necessity to communicate with children through professionals (psychologists, social workers, or other experts) which has not been done in all legal procedures, due to lack of available time or resources.

Finally, Ombudsperson raised a concern over the role of Specialized Legal Guardians in representation of children as to whether they represent child's opinion or his/her own opinion on the best interest of a child. ${ }^{365}$ The survey showed that the majority of Specialized Legal Guardians require from the Court what they consider to be the best interest of a child, without taking into consideration child's opinion which they are obliged to do, according to the Convention on Rights of the Child. ${ }^{366}$

\section{LEGAL GUARDIANSHIP OF UNACCOMPANIED MINOR MIGRANTS IN CROATIA}

The second aspect of child guardianship in Croatia is related to the appointment of specialized guardians to children who are foreign nationals and can find themselves in Croatia either in transit towards another country, as asylum applicants, victims of child trafficking or other categories of minor migrants without parental care. In this paper, I will refer to all categories of such children as unaccompanied minors.

The European Union Member States have a legal obligation to provide legal or other form of representation to unaccompanied minor migrants. This obligation was set in 2003 by Article 19.1 of Council Directive 2003/9/EC of 27 January 2003 laying down minimum standards for the reception of asylum seekers:

"Member States shall as soon as possible take measures to ensure the necessary representation of unaccompanied minors by legal guardianship or, where necessary, representation by an organization which is responsible for the care and well-being of minors or by any other appropriate representation. Regular assessments shall be made by the appropriate authorities".

Still, since the adoption of Directive 2003/9/EC up to date, we still do not have a common definition of legal guardianship of unaccompanied minors in Europe, which poses numerous problems, because there is a variety of legal solutions across the EU. Thus, migrant unaccompanied child might receive different forms of legal representation across the

\footnotetext{
${ }^{363}$ Ombudsperson for Children, Report on Work of Ombudsperson for Children for 2020, p. 196.

${ }^{364}$ Ibid.

${ }^{365}$ Ibid.

${ }^{366}$ Ibid.
} 
EU. ${ }^{367}$ As indicated in the report entitled "Towards a European Network of Guardianship Institutions", one form of representation is the one provided in the sense of Article 19 of Directive 2003/9/EC, while the other one is providing guardians as independent representatives responsible for the well-being of the child. ${ }^{368}$ The same report outlines that a guardian for unaccompanied minor should ensure that a separated child's welfare needs are be properly safeguarded within the context of the asylum determination and immigration process and that their support and care needs are be met by all responsible agencies. ${ }^{369}$

Croatian appointment of legal guardianship to unaccompanied minors is regulated by the Family Law and by the Protocol on Procedure with Unaccompanied Minors ${ }^{370}$ The Protocol establishes the national system of proceedings by defining the duties, methods and deadlines for dealing with unaccompanied children, in order to provide timely and effective protection of their rights and interests. ${ }^{371}$ The Protocol sets the following tasks of Social Worker/appointed Guardian: establishing communication (via interpreter) and allows the child to express needs, conducting an initial assessment of the needs of an unaccompanied child, informing the unaccompanied child of all facts and circumstances in an appropriate manner, suitable for child's age, maturity and understanding (especially on rights, obligations, available services and access to international protection) and ensuring the child's right to express opinions and needs, actively participating in the identification process in support of the child, informing the unaccompanied child of the rights and obligations during and after the procedure of identification, the right to a special guardian, as well as access to all other rights, ensuring that the procedure is conducted in a manner adapted to the unaccompanied child, representing the unaccompanied child in the proceedings for which he is appointed: taking care that procedures and all decisions are made for the benefit of the unaccompanied child, possibility to express an intention on behalf of the child if, in the return procedure he/she assesses that international protection is necessary with regard to the child's personal and other life circumstances. Further, in the case of suspected age claim, the Social Worker addresses suspicion as to the child's age, introduces him/her to age assessment procedures (including medical age testing) and possible consequences. The Social Worker pays special attention to risk indicators in terms of whether the unaccompanied child is a victim of trafficking in human beings and declares any justified suspicion in order to initiate the procedures of the national referral mechanism for cases identification of victims of trafficking. ${ }^{372}$

The Protocol stipulates that Specialized Guardian needs to participate in initial assessment of child's needs, health examination, age assessment, has accommodation related tasks (unaccompanied children in Croatia are accommodated in social welfare institutions) and

\footnotetext{
${ }^{367}$ NIDOS Foundation, Towards a European Network of Guardianship Institutions, 2005, https://www.nidos. nl/en/home/nidos-en-europa/european-guardianship-network-egn/

${ }^{368}$ Ibid. p. 10.

${ }^{369}$ Ibid, p. 7.

${ }^{370}$ Protocol was adopted in 2018 by the Government of Republic of Croatia, available at: https://mrosp.gov.hr/ istaknute-teme/obitelj-i-socijalna-politika/obitelj-12037/djeca-i-obitelj-12048/djeca-bez-pratnje-12060/12060

371 Ibid. p. 3.

${ }^{372}$ Ibid. pp. 8-9.
} 
subsequent visitation duties, selects legal aid provider and has other related numerous tasks.

As we can see from the above list, the tasks of a Specialized Guardian (usually Social Worker) are very extensive and almost impossible to undertake if there is no permanent translation service provided. Currently, Croatian guardianship system for migrant children relies on traditional live interpretation services (also used by the Courts) which are expensive and impractical - in other countries they are, in fact, being replaced by phone or Web-based live translation services. This unavailability of translation is one of the major obstacles in Social Workers ability to communicate with a child and thus, being able to undertake all the necessary tasks. ${ }^{373}$

The second obstacle to effective provision of above mentioned services prescribed by the Protocol is case-overload by Social Workers, due to which they are unable to dedicate necessary attention and time to unaccompanied minor migrants and effectively resolve all the issues they have. ${ }^{374}$ Interviews with unaccompanied minors in Croatia conducted in 2019 demonstrated that, in some cases, unaccompanied minors did not even have a chance to meet their Specialized Guardians, which can most probably be attributed to work overload of Social Workers. ${ }^{375}$ The same concern has been raised by Ombudsperson for Children, who pointed out that "it seems the role of Social Workers as Specialized Guardians is purely formal, as appointed guardians are "not in regular contact with minors, often meet them only when required by law for expression of requirement for international protection and thus, cannot fully protect their interests and rights." ${ }^{376}$ Ombudsperson further reports that during Covid pandemic, Specialized Guardians did not have online or phone contacts with unaccompanied minor migrants. ${ }^{377}$

The third obstacle to effective protection of rights of unaccompanied minors in terms of specialized guardianship lies in the weak coordination of various aspects of their legal protection. Current insufficient coordination between education, health care and social welfare systems prevents them from enjoying their fundamental rights, particularly important as for the access to schooling, full health care coverage and current practice of accommodation of unaccompanied minors in Centres for Children with Behaviour Disorders, which should be replaced by foster care accommodation (currently stipulated by the law, but not implemented in practice)..$^{378}$

The fourth obstacle to effective guardianship protection of minors is insufficient professional training and lack of supervision of Social Workers appointed to be Specialized Guardians. ${ }^{379}$ This involves their unsatisfactory knowledge of rights and procedures stipulated in Protocol, leading to violations of the child's best interest standard as

\footnotetext{
${ }^{373}$ NIDOS, Centar za nestalu i zlostavljanu djecu, Foster Care for Unaccompanied Minors, Report on Croatia, Stitching Nidos, The Netherlands, 2019, p. 17.

${ }^{374}$ Cf. Ombudsperson for Children, Report on Work of Ombudsperson for Children for 2020, p. 156.

${ }^{375}$ Ibid. ft. 33.

${ }^{376}$ Ombudsperson for Children, Report on Work of Ombudsperson for Children for 2020, p. 157.

377 Ibid.

${ }^{378}$ Cf. ibid. and Ombudsperson for Children, Report on Work of Ombudsperson for Children for 2020, p. 156, https://dijete.hr/izvjesca/izvjesca-o-radu-pravobranitelja-za-djecu/

${ }^{379}$ Ombudsperson for Children, Report on Work of Ombudsperson for Children for 2020, p. 156.
} 
stipulated by the Convention on Rights of the Child. ${ }^{380}$ Consequently, the Ombudsperson's recommended the professionalization of unaccompanied minors' specialized guardianship role, so as to facilitate full recognition of their internationally recognized rights. ${ }^{381}$

Finally, there is legally unjustified and even unlawful practice in Croatia to appoint a specialized guardian from the group of people with whom unaccompanied minor arrived to the country, and who claim to be a relative of the child. ${ }^{382}$ As those claims are not verified prior to appointment, Ombudsperson emphasized that nine of such appointments in 2020 were contrary to the Protocol and can be engendering a child's safety due to the fact that accompanying adults can be traffickers, people smugglers or simply do not have sufficient knowledge and skills to undertake guardianship role in the child's best interest. ${ }^{383}$

\section{ADULT LEGAL GUARDIANSHIP IN PRACTICE: ARE MENTALLY DISABLED PERSONS IN CROATIA INCAPACITATED OR SIMPLY INSUFFICIENTLY SUPPORTED?}

Until recently, Croatia applied a full incapacitation approach through legal incapacitation of persons with mental or intellectual disabilities without engaging in proper assessment procedure as to whether the person could indeed jeopardize his/her interests. This practice was mainly used to allow others to consent to the placement of mentally ill person in institutional settings or to facilitate involuntary hospitalizations or involuntary medical treatments. ${ }^{384}$ This was done in spite of the legal provision stating that "deprivation of legal capacity does not mean inability to give consent, so, before the application of a medical procedure, the ability to give consent must also be determined in the case of a person deprived of legal capacity. ${ }^{385}$ Legal incapacitation of mentally impaired persons in Croatia used to circumvent beneficiary's resistance to institutional accommodation or medical treatment ${ }^{386}$ constituted a severe violation of human rights of a person with disability, being one of the most serious violations of international human rights framework. The line Ministry initiated review procedures for all decisions of legal incapacitation of mentally

\footnotetext{
${ }^{380}$ Ibid, p. 157.

${ }^{381}$ Ibid.

382 Ibid.

${ }^{383}$ Ibid.

384 "Committee on the Rights of Persons with Disabilities in General Comment No. 1 (2014) of Art. 12. Convention on rights of persons with disabilities states that... "Segregation of persons with disabilities in institutions and further a ubiquitous and dangerous problem that violates a number of rights guaranteed by the Convention. The problem is exacerbated by widespread deprivation of legal capacity of persons with disabilities, which allows others to consent to their placement in institutional settings. (...) ". In the Guidelines on Art. 14. of the Convention on the Rights of Persons with Disabilities states that coercive detention of persons with disabilities on the basis of the danger or threat they pose, the alleged the need for care or treatment, or other reasons related to impairment or medical diagnosis, is contrary to the right to liberty and constitutes arbitrary deprivation of liberty," cited in: Ombudsperson for Persons with Disabilities Annual Report for 2019, p. 58. ${ }^{385}$ Article 12, p. 3 of the Law on the Protection of Persons with Mental Disabilities (Official Gazzette Number 76/14). ${ }^{386}$ Ibid. pp. 212-21 and cf. „Placement in closed settings without the consent of the individual concerned should always be considered a deprivation of liberty and subjected to the safeguards established under Article
} 
impaired persons brought between November 2015 and November 2020. ${ }^{387}$

The right to legal capacity is a prerequisite for the exercise of all other rights, some of which are particularly relevant for the persons with disabilities, such as the right to independent living in the community with the support and decision on placement in a psychiatric hospital, or the right to decide on treatment and all procedures performed for the purpose of treatment. ${ }^{388}$ Ombudsperson's for Persons with Disabilities recommended the promotion of "their empowerment, self-advocacy, independence, autonomy and, above all, maintaining control over one's own life also by making decisions about it". This Ombudsperson had previously called for an urgent legislative changes to implement international legal obligations whereby the human rights of persons with long-term physical, mental, intellectual or sensory disabilities would not be restricted, but instead, their legal capacity would be preserved and respected.

Legal incapacitation of disabled persons in Croatia was clearly used to fill the gaps in service provision necessary for independent living in community and social inclusion, such as transportation, rehabilitation, personal assistant, community nurse, etc. Therefore, the Ombudsperson pointed out the necessity to develop and expand existing services to support the quality of life of people with disabilities in their own homes, preventing their separation, including comprehensive mental health care in the community. ${ }^{389}$

Another troublesome aspect of legal incapacitation in order to facilitate institutionalisation of beneficiary lay in the inability of a person deprived of legal capacity to submit a request for judicial review of such decision or appeal it. ${ }^{390}$ Incapacitated persons are only entitled to require a review of the decision on deprivation of legal capacity, but are not authorized appellants against a decision on the involuntary accommodation submitted and approved by their guardians. This is a clear-cut case of denial of access to justice and deprivation of freedom. ${ }^{391}$

In Croatia, another problematic issue related to incapacitation of disabled persons, is the fact that, in institutional settings, a considerable of beneficiaries are under the guardianship of service provider employees. The Ombudsperson reported on as many as 19 persons being under the guardianship of one employee who cannot adequately protect the interests of persons deprived of legal capacity. ${ }^{392}$ Guardians who are service providers are also in a conflict of interest and should not be appointed to that role, in order to avoid the possible abuses of Art. 248 of the Family Law. ${ }^{393}$

Finally, there is a need to urgently introduce safeguards to prevent abuse of persons with mental disabilities for unlawful, fraudulent contractual dealings and loan agreements

5 of the European Convention on Human Rights, Council of Europe, Commissioner for Human Rights, 2021, Who gets to decide? Right to legal capacity for persons with intellectual and psychosocial disabilities.

${ }^{387}$ Ombudsperson for Persons with Disabilities Annual Report for 2019, pp. 54-55.

${ }^{388}$ Ibid.

${ }^{389}$ Ibid.

${ }^{390}$ Ibid. pp. 213-214.

${ }^{391}$ Ibid.

${ }^{392}$ Ibid. p. 60.

${ }^{393}$ Ibid. 
without the approval of a guardian, given legal incapacitation is visible only in the birth certificate, but not in other ID documents. Ombudsperson thus recommended the introduction of a safeguard through a supported decision-making system, so as to protect incapacitated beneficiary in conclusion of legal transactions and/or disposal of property rights from becoming a debtor of the loan agreement. ${ }^{394}$

In 2017, the Croatian Government made a formal step forward by committing to make a shift from substitute decision making to supported decision making by way of adoption of the Strategy for Equal Opportunities for Persons with Disabilities ${ }^{395}$ in line with Art. 12. of the Convention's obligation of the state to ensure the right to support independent decision-making. In the time of writing of this paper (September 2021), Croatia still has substitute decision-making for mentally impaired beneficiaries, provides summary legal incapacitation of mentally impaired individuals and still has not effected a single legislative change or otherwise introduced support-decision mechanism for disabled adults.

\section{CONCLUSION}

Legal representation of children and adults is a theme which should constantly be under close scrutiny and review of legal scholars, jurists, judges and lawyers, because it is the area where we can legally allow gross violations of human rights under the pretext of the "best interest" of the beneficiary. If a child or a mentally impaired adult cannot represent his/her interests and has no possibility to have his/her voice heard, we are preventing them from accessing justice and violating primarily the Convention on the Rights of a Child and the Convention on Rights of Persons with Disabilities, and also numerous other international human rights conventions. This paper points out the most urgent gap areas in legal regulation of guardianship for children (domestic and foreign nationals) in Croatia, as well as the key problem issues related to the protection of the most fundamental right of persons with disabilities - right to legal existence and ability to decide on one's life choices- which is being annulled by legal incapacitation and appointment of a guardian.

The paper identifies several groups of long-standing issues linked to legal gaps and gaps in provision of safeguards to facilitate meaningful, rights-based representation. In the area of child representation, there is insufficient number of appointed Specialized Child Legal Guardians and subsequently, insufficient contacts are effected with children. Furthermore, skills and professional competencies of appointed guardian jurists to communicate with children in vulnerable situations and necessity to communicate with children through professionals (psychologists, social workers, or other experts) is not practiced all legal procedures due to lack of available time or resources. Concerning survey results show that the majority of Croatian Specialized Legal Guardians require from Court what they consider to be the best interest of a child, without taking into consideration child's opinion, thus violating the Convention on Rights of the Child.

${ }^{394}$ Ibid.

${ }^{395}$ Government of Republic of Croatia, National Strategy for Equal Opportunities for Persons with Disabilities for the Period 2017-2020, Official Gazette Number 42/2017. 
In terms of legal representation of interests of unaccompanied minor migrants, five areas of concern obstructing effectiveness of guardianship were outlined in the paper: overly extensive list of tasks of child guardians coupled with unavailability of translation services which prevents communication between a Social Worker and a child; work overload of guardians and inability to meet with unaccompanied minors; weak coordination of various aspects of their legal protection (access to schooling, full health care coverage and current practice of accommodation of unaccompanied minors); insufficient professional training and lack of supervision of Social Workers appointed to be Specialized Guardians and legally unjustified and even unlawful practice in Croatia to appoint a specialized guardian from the group of people with whom unaccompanied minor arrived to the country and who claims to be a relative of a child.

When it comes to persons with mental disabilities, there are also numerous areas of concern. In Croatia, full legal incapacitation was applied almost by default for all persons with mental disability, often without proper assessment of level of understanding and ability to make decisions, often without proper explanation to the beneficiary and his/her family of the legal implications of such incapacitation. This practice was used to circumvent involuntary institutionalization or medical treatments of mentally impaired persons, which constituted a gross violation of Convention on Rights of Persons with Disabilities. Four years after the adoption of Croatian Strategy for Equal Opportunities for Persons with Disabilities, desk research revealed that no progress was made in terms of necessary shift from substitute-decision making to support-decision making for disabled persons. Nonetheless, there is hope that this paper might shed some light on the most important safeguards necessary to provide effective legal representation of children and adults, with a prospect that adult representation in Croatia will soon transform from surrogate -decision making to supported-decision making. For the moment, incapacitation is still used to compensate for the lack of available support services for disabled persons. 


\section{LIST OF REFERENCES}

Bach, M., Kerzner, L., 2010, A New Paradigm for Protecting Autonomy and the Right to Legal Capacity', prepared for the Law Commission of Ontario, p 16.

Burningham, S., 2009, Developments in Canadian Adult Guardianship and Co-DecisionMaking Law, 8 Dalhousie J. Legal Stud. 119.

Crampton, A., 2004, The Importance of Adult Guardianship for Social Work Practice, Journal of Gerontological Social Work, 43:2-3, 117-129, DOI: 10.1300/J083v43n02_08.

Dhanda, A., 2007, Legal capacity in the Disability Rights Convention: Stranglehold of the past or lodestar for the future?, 34 Syracuse Journal of International Law \& Commerce, p. 429 ff.

Minkowitz, T, 2007, The United Nations Convention on the Rights of Persons with Disabilities and the right to be free from nonconsensual psychiatric interventions, 34 Syracuse Journal of International Law \& Commerce, p. 405f.

\section{LAWS, CONVENTIONS AND REGULATIONS}

Constitution of Republic of Croatia, (Official Gazette Number 56/90, 135/97, 08/98, 113/00, 124/00, 28/01, 41/01, 55/01, 76/10, 85/10, 05/14).

Convention on the Rights of the Child, Adopted and opened for signature, ratification and accession by General Assembly resolution 44/25 of 20 November 1989, entry into force 2 September 1990.

Convention on the Rights of Persons with Disabilities, Official Gazette - International Agreements, No. 06/07, 03/08 and 05/08.

Family Law (Official Gazette Number 103/15, 98/19).

Law on Center for Specialized Legal Guardianship (Official Gazette Number 47/20).

Law on Protection of Persons with Mental Disabilities (Official Gazette Number 76/14). Law on Social Welfare (Official Gazette Number 157/13, 152/14, 99/15, 52/16, 16/17, 130/17, 98/19, 64/20, 138/20).

Law on Social Work, (Official Gazette Number 16/19).

Protocol was adopted in 2018 by the Government of Republic of Croatia, available at: https://mrosp.gov.hr/istaknute-teme/obitelj-i-socijalna-politika/obitelj-12037/djecai-obitelj-12048/djeca-bez-pratnje-12060/12060.

Government of Republic of Croatia, National Strategy for Equal Opportunities for Persons with Disabilities for the Period 2017-2020, Official Gazette Number 42/2017.

\section{REPORTS}

Committee on the Rights of Persons with Disabilities, General comment No. 1 (2014), Article 12: Equal recognition before the law, CRPD/C/GC/1, p. 3, point 12.

Council of Europe, Commissioner for Human Rights, 2021, Who gets to decide? Right to legal capacity for persons with intellectual and psychosocial disabilities, pp. 10-11. 
European Union Agency for Fundamental Rights, 2014, Guardianship for children deprived of parental care, A handbook to reinforce guardianship systems to cater for the specific needs of child victims of trafficking, p. 13.

Government of Alberta, Canada, https://open.alberta.ca/publications/guardianshipgeneral-overview.

NIDOS Foundation, Towards a European Network of Guardianship Institutions, 2005, https://www.nidos.nl/en/home/nidos-en-europa/european-guardianship-network-egn/

Ombudsperson for Children, Report on Work of Ombudsperson for Children for 2020, https://dijete.hr/izvjesca/izvjesca-o-radu-pravobranitelja-za-djecu/.

Ombudsperson for Children, Report on Work of Ombudsperson for Children for 2019, https://dijete.hr/izvjesca/izvjesca-o-radu-pravobranitelja-za-djecu/

UN Committee on the Rights of the Child General Comment No. 6 CRC/GC/2005/6 and the UN Alternative care guidelines A/HRC/11/L.13, cited in: European Union Agency for Fundamental Rights, 2014, Guardianship for children deprived of parental care, A handbook to reinforce guardianship systems to cater for the specific needs of child victims of trafficking. 